\title{
Estimating the frequency of Asian cytochrome $B$ haplotypes in standard European and local Spanish pig breeds
}

\author{
Alex Clop ${ }^{\mathrm{a}}$, Marcel Amills ${ }^{\mathrm{a}}$, José Luís Noguera ${ }^{\mathrm{b}}$, Ana Fernández ${ }^{\mathrm{c}}$, \\ Juan CAPOTE ${ }^{\mathrm{d}}$, Maria Misericòrdia RAMóN ${ }^{\mathrm{e}}$, Lucía KeLLY ${ }^{\mathrm{f}}$, \\ James M.H. KIJAS ${ }^{\mathrm{g}}$, Leif ANDERSSON${ }^{\mathrm{g}}$, Armand SÀNCHEZ ${ }^{\mathrm{a} *}$ \\ ${ }^{a}$ Departament de Ciència Animal i dels Aliments, Facultat de Veterinària, \\ Universitat Autònoma de Barcelona, Bellaterra 08193, Spain \\ b Area de Producció Animal, Centre UdL-IRTA, Alcalde Rovira Roure 177, \\ Lleida 25198, Spain \\ ${ }^{c}$ Area de Genética y Mejora Animal, SGIT-INIA, Ctra. De la Coruña km. 7, \\ Madrid 28040, Spain \\ ${ }^{\mathrm{d}}$ Instituto Canario de Investigaciones Agrarias, Apartado de correos 60, \\ La Laguna 38200, Spain \\ e Departament de Biologia, Laboratori de Genètica, Universitat de les Illes Balears, \\ Ctra. Valldemossa, km 7.5, Palma de Mallorca 07071, Spain \\ ${ }^{\mathrm{f}}$ Departamento de Biología Celular y Molecular, Facultad de Veterinaria, Universidad \\ de la República, Av. Lasplaces 1550, Montevideo, CP 11600, Uruguay \\ ${ }^{\mathrm{g}}$ Department of Animal Breeding and Genetics, Swedish University of Agricultural Sciences, \\ Uppsala Biomedical Centre, 751 24, Uppsala, Sweden
}

(Received 20 December 2002; accepted 27 August 2003)

\begin{abstract}
Mitochondrial DNA has been widely used to perform phylogenetic studies in different animal species. In pigs, genetic variability at the cytochrome B gene and the D-loop region has been used as a tool to dissect the genetic relationships between different breeds and populations. In this work, we analysed four SNP at the cytochrome B gene to infer the Asian (A1 and A2 haplotypes) or European (E1 and E2 haplotypes) origins of several European standard and local pig breeds. We found a mixture of Asian and European haplotypes in the Canarian Black pig (E1, A1 and A2), German Piétrain (E1, A1 and A2), Belgian Piétrain (E1, A1), Large White (E1 and A1) and Landrace (E1 and A1) breeds. In contrast, the Iberian (Guadyerbas, Ervideira, Caldeira, Campanario, Puebla and Torbiscal strains) and the Majorcan Black pig breeds only displayed the E1 haplotype. Our results show that the introgression of Chinese pig breeds affected most of the major European standard breeds, which harbour Asian haplotypes at diverse frequencies (15-56\%). In contrast, isolated local Spanish breeds, such as the Iberian and Majorcan Black pig, only display European cytochrome B haplotypes, a feature
\end{abstract}

\footnotetext{
* Corresponding author: Armand.Sanchez@uab.es
} 
that evidences that they were not crossed with other Chinese or European commercial populations. These findings illustrate how geographical confinement spared several local Spanish breeds from the extensive introgression event that took place during the 18th and 19th centuries in Europe.

mitochondria / cytochrome B / pig breeds / Asian and European haplotypes / introgression

\section{INTRODUCTION}

Pig mitochondrial DNA (mtDNA) is a $16 \mathrm{~kb}$ circular molecule including 13 protein-coding genes, 22 tRNA and genes responsible for $12 \mathrm{~S}$ and $16 \mathrm{~S}$ rRNA $[7,15]$. Phylogenetic analysis of the porcine mitochondrial genome has revealed that Wild Boar subspecies were independently and simultaneously domesticated in Asia and Europe 9000 YBP [2, 6-8, 10]. Major European and Asian mtDNA clades diverged well before this domestication event and the estimates for the time of divergence range from 58000 to 900000 YBP $[1,2,6,7,10]$. Two distinct European clades denoted E1 and E2 have also been characterised by Giuffra and coworkers [2]. The former one has been found in most of the European Wild Boars and domestic pig breeds, whereas E2 has been detected in three Wild Boars from Italy. The major cytochrome $\mathrm{B}(C y t B)$ haplotypes can be easily distinguished on the basis of four single nucleotide polymorphisms located at positions 15036, 15038, 15041 and $15045 \mathrm{bp}$ of the complete sequence of the pig mtDNA (numbering of positions follows Ursing and Arnason [17]).

In this paper, we analysed cytochrome B $(C y t B)$ haplotypes in the Iberian, Majorcan Black and Canarian Black Spanish autochthonous breeds and several European standard breeds such as the Large White, Landrace, and Piétrain. Our main goal was to compare the prevalence of Asian haplotypes in three of the major commercial European pig breeds with regards to three local European pig populations which have remained geographically isolated for a long time span.

\section{MATERIALS AND METHODS}

\subsection{Animal material}

We analysed 82 samples from three autochthonous Spanish breeds including the Majorcan Black pig (MB, $n=21)$, Canarian Black pig $(\mathrm{CB}, n=11)$ and Iberian (IB, $n=50)$. The IB samples belonged to the Torbiscal $(n=24)$, Ervideira $(n=5)$, Caldeira $(n=5)$, Puebla $(n=5)$, Guadyerbas $(n=6)$ and Campanario $(n=5)$ strains. Moreover, we typed $C y t B$ from 257 samples corresponding to German Piétrain (GPI, $n=69$ ), Belgian Piétrain (BPI, $n=$ 33), Large White (LW, $n=43$ ), and Landrace (LD, $n=112$ ) breeds (Tab. I). 
Table I. Distribution of European (E1 = TGCG and E2 = TGTG ) and Asian (A1 = CATA and A2 = CATG) haplotypes in several European standard and local pig breeds. The Iberian samples belong to the Torbiscal $(n=24)$, Ervideira $(n=5)$, Caldeira $(n=5)$, Puebla $(n=5)$, Guadyerbas $(n=6)$ and Campanario $(n=5)$ strains. The SNP are located at position 15036 (T/C), 15038 (G/A), 15041 (C/T) and 15045 (G/A) from the complete sequence of pig mtDNA [6], respectively.

\begin{tabular}{lccccc}
\hline \multirow{2}{*}{ Breed } & \multicolumn{4}{c}{ Haplotype } & Total \\
\cline { 2 - 5 } & E1 & E2 & A1 & A2 & \\
\hline Iberian pig & 50 & 0 & 0 & 0 & 50 \\
Majorcan Black pig & 21 & 0 & 0 & 0 & 21 \\
Canarian Black pig & 3 & 0 & 3 & 5 & 11 \\
German Piétrain & 40 & 0 & 2 & 27 & 69 \\
Belgian Piétrain & 28 & 0 & 5 & 0 & 33 \\
Large White & 19 & 0 & 24 & 0 & 43 \\
Landrace & 94 & 0 & 18 & 0 & 112 \\
& & & & & \\
Total & 255 & 0 & 52 & 32 & 339 \\
\hline
\end{tabular}

The LW and LD pigs typed in this experiment belong to two different maternal lines imported from France in 1980 and they have been selected for litter size, backfat and growth performance. The GPI pigs were imported from Germany and they have been selected for backfat and growth performance. The BPI pigs belong to the original Piétrain purebred population originating in Belgium in 1920 and they have been used as a source of genetic material in a Belgian artificial insemination centre [3].

\subsection{Amplification of the $C y t B$ gene}

Total DNA was extracted from $0.5 \mathrm{~mL}$ of whole blood using the DNA Isolation Kit for Mammalian Blood (Roche Diagnostics S.L., Barcelona, Spain) or a standard phenol-chloroform and ethanol precipitation method. Briefly, white blood cells were repeatedly washed with $0.5 \mathrm{~mL}$ TE (Tris $10 \mathrm{mM}$, EDTA $1 \mathrm{mM}, \mathrm{pH} 8.0)$ and incubated in $0.4 \mathrm{~mL}$ lysis buffer $(50 \mathrm{mM} \mathrm{KCl}, 10 \mathrm{mM}$ Tris, $2.5 \mathrm{mM} \mathrm{MgCl}_{2}, 0.5 \%$ Tween 20, $\mathrm{pH}$ 8.3) plus $10 \mu \mathrm{L}$ proteinase $\mathrm{K}$ $\left(10 \mathrm{mg} \cdot \mathrm{mL}^{-1}\right)$ at $56{ }^{\circ} \mathrm{C}$ for $4 \mathrm{~h}$. Nucleic acids were purified by chlorophorm extraction and precipitated with two volumes of ethanol. The DNA pellet was washed with ethanol $70 \%$ and resuspended in ultrapure water. We amplified a sequence of $131 \mathrm{bp}$ of the $C y t B$ gene. This sequence contains four SNP located at positions $47(\mathrm{~T} / \mathrm{C}), 49(\mathrm{G} / \mathrm{A}), 52(\mathrm{C} / \mathrm{T})$ and $56(\mathrm{G} / \mathrm{A})$ bp of the PCR product that correspond to positions 15036, 15038, 15041 and $15045 \mathrm{bp}$ of the pig mtDNA. The E1 (TGCG) and the E2 (TGTG) haplotypes are European, whereas the A1 (CATA) and the A2 (CATG) haplotypes have an Asian origin $[2,5]$. The amplification of the target region was performed in a final 
volume of $20 \mu \mathrm{L}$ containing $50 \mathrm{mM} \mathrm{KCl}, 15 \mathrm{mM}$ Tris- $\mathrm{HCl}$ at $\mathrm{pH} 8.0,1.5 \mathrm{mM}$ $\mathrm{MgCl}_{2}, 200 \mu \mathrm{M}$ dNTP, $0.5 \mu \mathrm{M}$ of the forward primer (FW: 5'-CGC CTA CGC TAT TCT ACG TTC A-3'), $0.5 \mu \mathrm{M}$ of the reverse primer (REV: 5'-GTG GTC GAA ATA TTA TGC CTC GTT-3'), 0.5 U of AmpliTaq Gold DNA polymerase (Applied Biosystems, Foster City, CA, USA) and 2 ng of genomic DNA. After denaturation at $95{ }^{\circ} \mathrm{C}$ for $10 \mathrm{~min}$, the reactions were heated for 30 cycles at $94{ }^{\circ} \mathrm{C}$ for $30 \mathrm{~s}, 54{ }^{\circ} \mathrm{C}$ for $30 \mathrm{~s}$ and $72{ }^{\circ} \mathrm{C}$ for $30 \mathrm{~s}$.

\subsection{Sequencing of the PCR product}

Amplified products were purified with the QIAquick PCR Purification kit (Qiagen, Servicios Hospitalarios, Barcelona, Spain). The purified PCR reaction was analysed by using either pyrosequencing [13] or a conventional Sanger dideoxy sequencing method [14]. Five IB pigs, five MB pigs and all the LW, LD and GPI pigs were analysed by pyrosequencing, whereas the remaining individuals were typed by conventional sequencing. We used the BigDye Terminator Cycle Sequencing v2.0 Ready Reaction kit (Applied Biosystems) and the reverse primer to perform Sanger dideoxy sequencing. The thermal profile was $94{ }^{\circ} \mathrm{C}$ for $3 \mathrm{~min}$, followed by 25 cycles of $94{ }^{\circ} \mathrm{C}$ for $10 \mathrm{~s}, 50{ }^{\circ} \mathrm{C}$ for $5 \mathrm{~s}$ and $60^{\circ} \mathrm{C}$ for $4 \mathrm{~min}$. Pyrosequencing was performed with the Luc $96^{\mathrm{TM}}$ SNP Reagent Kit (Pyrosequencing AB, Uppsala, Sweden) according to the instructions of the manufacturer. The final volume of the reaction was $40 \mu \mathrm{L}$ containing $20 \mathrm{mM}$ Tris-Acetate, $5 \mathrm{mM} \mathrm{MgCl}_{2}, 15$ pmol of the pyrosequencing primer PYR, 5'-GATTAGGATGGAGGCT-3' and the PCR fragment immobilised with M-280 streptavidin dynabeads (Dynal AS, Oslo, Norway).

\section{RESULTS AND DISCUSSION}

The prevalence of $c y t B$ and D-loop European and Asian haplotypes had been previously studied in major European commercial breeds such as the Large White, Landrace, Duroc, Hampshire and others [2,7,10]. These studies demonstrate that most of these standard breeds had been extensively introgressed with Asian alleles. However, to the best of the authors knowledge there is not any estimate of the frequency of Asian haplotypes in local breeds with a limited geographical distribution and that have been selected for productive goals mostly related to the manufacture of specialised and highly-priced products.

Partial sequencing of the $c y t B$ gene in standard breeds demonstrated the presence of Asian cytB haplotypes in LW and LD (Tab. I). There is ample historical evidence indicating that many Chinese pigs were imported into England from 1770 to 1860 and introgressed into the English populations 
which influenced the development of the LW, Berkshire, Small White and Middle White breeds [5]. The main objective of this introgression was to accelerate fattening and achieve an earlier maturity [5]. Similarly, there are abundant historical records suggesting that the LD breed was produced by crossing British and Chinese breeds with native land pig populations during the 18th and 19th centuries. Our estimate of the prevalence of Asian haplotypes in LW and LD was quite consistent with the data reported by Giuffra [2] and coworkers and suggests that LD was affected to a lesser extent than LW by the introgression of Asian alleles. This conclusion is supported by the phylogenetic analysis of D-loop sequences of several European and Asian breeds, which demonstrated that LW D-loop sequences clustered with their Asian orthologs but not with the European ones [7].

We have also analysed for the first time the prevalence of $c y t B$ haplotypes in the BPI and GPI breeds. The BPI breed originated around the small village of Piétrain in Belgium in 1920, but its ancestry still remains obscure [5]. Several authors suggest that the BPI breed was likely produced by the mixture of local Belgian breeds and other European populations such as the Berkshire, LW, Bayeux of Normandy, Périgord and Tamworth [5]. CytB genotyping of 33 BPI pigs demonstrated that the A1 haplotype has a frequency of $15 \%$ (Tab. I). This finding is consistent with the participation of LW, and other introgressed breeds, in the foundation of BPI. In contrast, GPI pigs displayed a high frequency of the A2 haplotype (39\%, Tab. I), which is a minority in other breeds. GPI is a composite breed resulting from the mixture of BPI, Belgian LD and other genetic backgrounds in order to increase the small body size and poor daily gain that characterises BPI pigs [11]. Likely, the A2 haplotype was introduced in the GPI population not through BPI but by the means of any of the other breeds that participated in its foundation.

The study of the $c y t B$ haplotype distribution in three Spanish breeds provided an interesting perspective of how the introgression of Chinese breeds that took place in Europe in the 18th and 19th centuries influenced local and isolated populations. We found that Asian $c y t B$ haplotypes are completely absent from the IB and MB breeds, whereas the CB breed shows an extremely high prevalence of the A2 haplotype (73\%, Tab. I). The particular historical events that resulted in the foundation of the IB and MB breeds and their geographical isolation may explain why we did not find any Asian $c y t B$ haplotype in these two populations. Iberian is the main Spanish pig breed due to the economic importance of its cured products and its population census. Iberian pigs are reared in the south-west of Spain and they are typically fat and black or red coloured or even black spotted, depending on their origin. The Torbiscal IB strain was generated in 1963 from four different crosses involving Negro 
Lampiño, Retinto and Dourado Alentejano IB pigs $[1,16]$, whereas Guadyerbas is a highly inbred strain that was derived from a small number of Negro Lampiño pigs in 1945 [15]. Other IB strains are Puebla, Campanario, Ervideira and Caldeira, the two latter ones originating from Portugal. In this way, these IB strains have emerged as a result of the mixture of ancestral autochthonous pig populations from the Iberian Peninsula. They have not been significantly introgressed with other Chinese or European breeds, probably due to the fact that IB pigs remained geographically isolated for a long time span. Our results were in good agreement with the $c y t B$ typing of IB pigs by Alves et al. [1] clearly demonstrating the absence of Asian $c y t B$ haplotypes in these Spanish autochthonous pig populations. Similarly, we did not find any evidence of introgression of Chinese breeds in the MB breed, which was described by the first time in the Majorca Island in the 19th century. MB pigs are black coated, lop-eared and extremely fat, and they have wattles in the neck. The origin of the MB breed is unclear but there is archaeological evidence suggesting the presence of pigs in Majorca as early as the 14th century B.C. [9]. These pigs were probably brought by the Phoenician colonisers being mixed with other swine breeds due to the invasion of the Balearic Islands by the Romans, and the Catalans $[4,9]$. The small effective size of this breed, the geographical confinement and the strong influence of Iberian black pigs on its development might explain the complete absence of Asian haplotypes in this breed.

The only Spanish breed that displayed Asian haplotypes was $\mathrm{CB}$, which is a black pre-Hispanic breed that is exclusively found on the Canary Islands. The origin of this breed is still a matter of debate. According to Robert et al. [12], the first settlers of the Canary Islands came from North Africa at the end of the third millennium B.C. This indigenous civilisation used pig derived products as a source of food and for clothing. The occurrence of multiple colonisation events and the conquest of the Canary archipelago by Spain in the 15 th century favoured the emergence of the CB breed from the mixture of Spanish, British and North African genetic backgrounds. Two hypotheses might explain the frequent presence of the A2 haplotype in CB. First, it is possible that this A2 haplotype was introduced in the $\mathrm{CB}$ breed due to the introgression of British breeds harbouring this particular haplotype. Conversely, it is possible that the A2 haplotype was present in the ancestral North African pig population that was brought by the first settlers of the Canary Islands. In fact, the CB breed shows several morphological traits, such as the presence of wrinkles in the skin and large ears over the eyes, that are distinctive of the Chinese breeds. Taken together, our results demonstrate that Asian haplotypes are ubiquitously distributed in most of the standard European pig breeds but not in local populations that have remained geographically isolated. As the next step, it would be interesting to type the $c y t B$ gene in African pig breeds to investigate from 
which of the two Asian and European domestication centers they originate and to dissect the complex mixture of forces and historical circumstances that have influenced pig domestication worldwide.

\section{ACKNOWLEDGEMENTS}

We are grateful to J. Caraballo and M. Castro for providing Canarian Black pig blood samples and to M. Georges and L. Moreau for extracting and providing total DNA from Belgian Piétrain blood samples. Thanks to A. Tejera Gaspar for helpful discussion and to G. Nyman for her contribution in the pyrosequencing work. We are also indebted to J.A. Castro and A. Picornell for technical assistance. Thanks to SIA "El Deheson del Encinar" (Toledo, Spain) and to COPAGA and Nova Genètica for providing Iberian, German Piétrain, Large White and Landrace blood samples. Alex Clop received a predoctoral fellowship from the Universitat Autònoma de Barcelona.

\section{REFERENCES}

[1] Alves E., Óvilo C., Rodríguez C., Silió L., Mitochondrial DNA sequence variation and phylogenetic relationships among Iberian pigs and other domestic and wild pig populations, Anim. Genet. 34 (2003) 319-324.

[2] Giuffra E., Kijas J.M., Amarger V., Carlborg O., Jeon J.T., Andersson L., The origin of the domestic pig: independent domestication and subsequent introgression, Genetics 154 (2000) 1785-1791.

[3] Hanset R., Dasnois C., Scalais S., Michaux C., Grobet L., Effet de l'introgression dans le génome Piétrain de l'allèle normal au locus de sensibilité à l'halothane, Genet. Sel. Evol. 27 (1995) 77-88.

[4] Jaume J., Picornell A., Ghio G., Castro J.A., Ramón M.M., El porc negre mallorquí. La genètica com a eina per la recuperació d'una raça autòctona, Revista de Ciència (IEB) 21 (1997) 105-117.

[5] Jones G.F., Genetic aspects of domestication, common breeds and their origin, in: Rothschild M.F., Ruvinsky A. (Eds.), The Genetics of the Pig, CAB International, Wellingford, Oxon, UK, 1998, pp. 17-50.

[6] Kijas J.M., Andersson L., A phylogenetic study of the origin of the domestic pig estimated from the near-complete mtDNA genome, J. Mol. Evol. 52 (2001) 302-308.

[7] Kim K.I., Lee J.H., Li K., Zhang Y.P., Lee S.S., Gongora J., Moran C., Phylogenetic relationships of Asian and European pig breeds determined by mitochondrial DNA D-loop sequence polymorphism, Anim. Genet. 33 (2002) 19-25.

[8] Lin C.S., Sun Y.L., Liu C.Y., Yang P.C., Chang L.C., Cheng I.C., Mao S.J., Huang M.C., Complete nucleotide sequence of pig (Sus scrofa) mitochondrial genome and dating evolutionary divergence within Artiodactyla, Gene 236 (1999) 107-114. 
[9] Mora J., Palou M., Sobrassada de Porc Negre, Govern Balear, Conselleria d'Agricultura i Pesca (1993).

[10] Okumura N., Kurosawa Y., Kobayashi E., Watanobe T., Ishiguro N., Yasue H., Mitsuhashi T., Genetic relationship amongst the major non-coding regions of mitochondrial DNAs in wild boars and several breeds of domesticated pigs, Anim. Genet. 32 (2001) 139-147.

[11] Porter V., Pigs: A Handbook to the Breeds of the World, Cornell University, Ithaca, New York, 1993.

[12] Robert A., Zamorano M.J., Ginés R., Argüello A., Delgado J.V., López J.L., Origen y estado actual del Cerdo Negro Canario, Arch. Zootec. 49 (2000) 291-296.

[13] Ronagui M., Úhlen M., Nyrén P., Real-time pyrophosphate detection for DNA sequencing, Science 281 (1998) 363-364.

[14] Sanger F., Nicklen S., Coulson A.D., DNA sequencing with chain-terminating inhibitors, Proc. Natl. Acad. Sci. USA 74 (1977) 5463-5467.

[15] Toro M.A., Rodrigáñez J., Silió L., Rodríguez M.C., Genealogical analysis of a closed herd of black hairless Iberian pigs, Cons. Biol. 14 (2000) 1843-1851.

[16] Toro M., Barragán C., Óvilo C., Rodrigáñez J., Rodríguez C., Silió L., Estimation of coancestry in Iberian pigs using molecular markers, Cons. Genet. 3 (2002) 309-320.

[17] Ursing B.M., Arnason U., The complete mitochondrial DNA sequence of the pig (Sus scrofa), J. Mol. Evol. 47 (1998) 302-306.

To access this journal online: www.edpsciences.org 